\title{
IOT BASED EFFICIENT SOLAR PANEL MONITORING
}

\author{
Mirsad Hyder Shah \\ Student, Technische Universitat Dortmund. \\ Dortmund, (Germany). \\ E-mail: itsmirsadhyder@yahoo.com ORCID: https://orcid.org/0000-0003-2476-5887
}

\begin{abstract}
Nasser Hassan Abosaq
Assistant Professor, Computer Science and Engineering Department. Yanbu University College, Yanbu Industrial City,

(Kingdom of Saudi Arabia).

E-mail: abosaqn@rcyci.edu.sa ORCID: https://orcid.org/0000-0003-1354-3170
\end{abstract}

\section{Gitación sugerida:}

Shah, M.H., y Abosaq, N.H. (2020). IoT based efficient solar panel monitoring. 3C Tecnología. Glosas de innovación aplicadas a la pyme, 9(4), 87-93. https://doi.org/10.17993/3ctecno/2020.v9n4e36.87-93 


\section{ABSTRACT}

The invention of smart grid has already outdated the conventional method of one way power productionsupply concept. While developed countries have already started to adopt smart meters, appliances and renewable energy sources; underdeveloped and developing countries are still facing power shortages every day. In the second Industrial Revolution, electricity was the main advancement and the recent Industrial Revolution 4.0 has pushed giant Production companies into the adoption and promotion of Renewable Energy sources. The integration of IoT and power systems has revolutionized the world in terms of power efficiency and real time monitoring. This paper discusses an experimental work done on how IoT can monitor the power/voltage and current production of a standalone renewable energy source i.e. a solar panel. This paper also discusses how to improve the solar panel efficiency by correcting the tilt angle of the solar panel. The monitoring of the solar panel is done via an inter-connected system using NodeMCU, Node-RED, Arduino and an MQTT channel. The monitoring of solar panels can be made easier by implementing the proposed work in a photovoltaic (PV) power plant. Moreover the monitoring of energy production will greatly enhance the health of the PV system. A 24\% increase in the power output has been noticed after the correction of the tilt angle which was corrected using a solar tracker.

\section{KEYWORDS}

IoT based Solar Panel, Solar monitoring, NodeMCU, Node-RED, MQTT, Tilt Correction using IoT, Azimuth Correction using IoT. 


\section{INTRODUCTION}

Internet of Things (IoT) has already made its way into numerous applications. From smart homes to IoT based management systems in Industries, IoT has been employed to make our lives much easier and dataaccessible. It is estimated that by 2025, there will be more than 21 Billion IoT devices (Symanovich, n.d.). The ease which IoT introduces in the monitoring of power production and consumption is unmatched.

\section{METHODOLOGY}

The components required for the integration of IoT with solar panel are as follows (Oukennou et al., 2019):

\subsection{NODEMCU}

NodeMCU is an open source firmware based on ESP8266 wifi-soc. NodeMCU provides access to the GPIO (General Purpose Input/Output) subsystem. It is mainly used for IoT based applications. (NodeMCU, 2014)

\subsection{INA219 CURRENT SENSOR}

After connecting it with INA219 which is a current shunt and power monitor, it monitors the shunt voltage and current coming from the solar panel. INA219 is basically a High side DC Current sensor which can detect current from a range of +3.2 to -3.2 Amperes and 26 Volts.

\subsection{NODE-RED}

Node-RED is a programming tool which wires the above hardware devices together. Node-RED is also an open source project. It has a web browser based flow editor with which JavaScript functions can be employed (Node-RED, n.d.). 


\subsection{ARDUINO}

Arduino software is a free Integrated Development Environment (IDE). It is open source application which can be downloaded from their website. It allows users to create interactive electronic circuits with program editions which can be uploaded, compiled in Arduino boards.

\subsection{MQTT}

MQTT is used as a communication channel between two or more devices. It is bandwidth efficient and consumes very little power. It can be used as a transport mechanism between the devices and IoT.

\section{WORKING}

The NodeMCU microcontroller or the ESP8266, collects the input parameters (Voltage, current and power) from the INA219 sensor. After the microcontroller is connected to the MQTT via Wi-Fi, we can collect the output from the NodeMCU after opening Node-RED. Since the privacy of our data should not be compromised, we can visualize the results via connecting a device to the Internet with the username/password. (Oukennou et al., 2019)

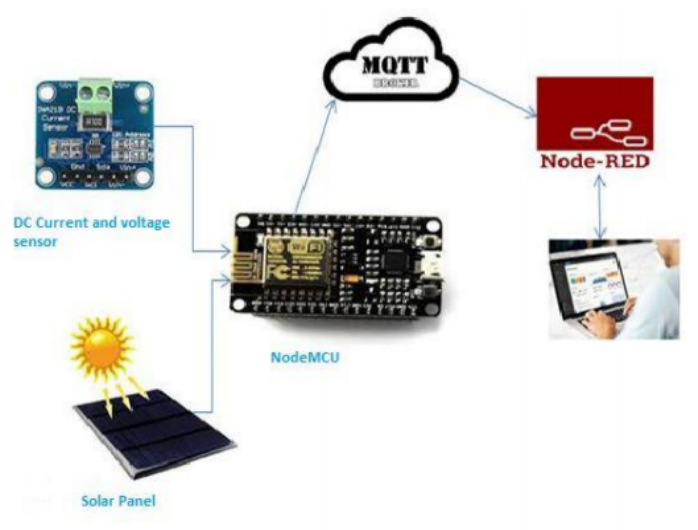

Graphic 1. System Architecture.

Source: (Oukennou et al., 2019). 


\section{CORRECTION OF TILT AND AZIMUTH ANGLE USING IOT}

The tilt angle describes the vertical angle of a solar panel. Azimuth angle is their horizontal facing in relation to the equator. For solar panels to perform best they should be directed accurately towards the sun. Users in the northern hemisphere should face their solar panels towards the south and vice versa. Due to magnetic declination, the inaccuracy of finding the true south hinders the solar panel's best performance (Wholesale Solar, 2018).

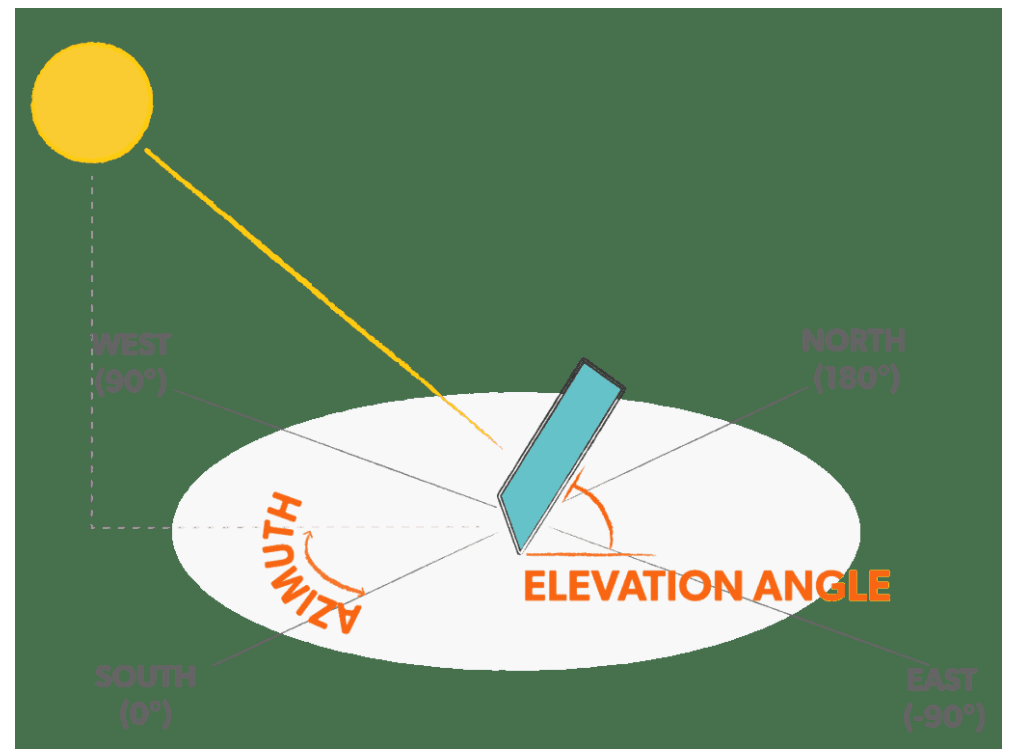

Graphic 2. Azimuth and tilt angle in relation to the equator.

Source: (Wholesale Solar, 2018).

A solar tracker is a device that orients the direction of the solar panel directly towards the sun. With employing IoT, solar panels can be made much more efficient. This can be done by providing accurate data to the microcontroller which then corrects the tilt angle. Brushless DC motors are employed under the solar panel which take hourly readings from the microcontroller and adjusts the tilt angle. 


\section{RESULTS}

This paper proposes a real time and low cost monitoring system for solar panel using NodeMCU which is connected to Node-Red. This system can help to measure PV system's productions: voltage, current and power. The table below compares the measured values of INA219 and a multimeter.

In Table 1, the monitoring of the solar panel has been carried out. These results were achieved with the combined setup of the Microcontroller, Sensors, Software and a multimeter. In Table 1, the measured power using a multimeter is much more accurate but dealing with a software using the current sensor is much easier.

Table 1. Results with NodeMCU and Node-RED setup.

\begin{tabular}{|c|c|c|}
\hline Measured power using INA219 & Measured Power using multimeter & Inaccuracy in results \\
\hline $24 \mathrm{~mW}$ & $24.4 \mathrm{~mW}$ & $0.4 \mathrm{~mW}$ \\
\hline $30 \mathrm{~mW}$ & $30.2 \mathrm{~mW}$ & $0.2 \mathrm{~mW}$ \\
\hline $33 \mathrm{~mW}$ & $33.4 \mathrm{~mW}$ & $0.4 \mathrm{~mW}$ \\
\hline $36 \mathrm{~mW}$ & $36.6 \mathrm{~mW}$ & $0.6 \mathrm{~mW}$ \\
\hline $37 \mathrm{~mW}$ & $37.3 \mathrm{~mW}$ & $0.3 \mathrm{~mW}$ \\
\hline
\end{tabular}

In Table 2, Voltage and Power readings with and without the correction of tilt and Azimuth angle have been discussed. As it can be inferred from the power readings with and without IoT, IoT provides a much higher power output. At time 12:00 p.m. the power with IoT is 24\% more than power without IoT.

Table 2. Results obtained after correcting tilt and Azimuth angle using loT.

\begin{tabular}{|c|c|c|c|c|}
\hline TIME & Voltage without lot & Voltage with loT & Power without loT & Power with loT \\
\hline $8: 00$ a.m. & $10 \mathrm{~V}$ & $12 \mathrm{~V}$ & $20 \mathrm{~mW}$ & $27 \mathrm{~mW}$ \\
\hline $10: 00$ a.m. & $15.27 \mathrm{~V}$ & $17.46 \mathrm{~V}$ & $26 \mathrm{~mW}$ & $32 \mathrm{~mW}$ \\
\hline $12: 00$ p.m. & $19.55 \mathrm{~V}$ & $21.65 \mathrm{~V}$ & $32 \mathrm{~mW}$ & $42 \mathrm{~mW}$ \\
\hline $14: 00$ p.m. & $19.71 \mathrm{~V}$ & $21.34 \mathrm{~V}$ & $35 \mathrm{~mW}$ & $42 \mathrm{~mW}$ \\
\hline $17: 00$ p.m. & $14.25 \mathrm{~V}$ & $18.62 \mathrm{~V}$ & $22 \mathrm{~mW}$ & $30 \mathrm{~mW}$ \\
\hline
\end{tabular}




\section{CONCLUSION}

IoT has already managed its way into our daily lives in the form of Smart homes. This paper discusses how IoT can be integrated with a standalone renewable energy source i.e. a solar panel. Typical Solar panels waste about $15-20 \%$ of their maximum power potential due to magnetic declination, this paper also involves IoT as to improve solar efficiency by correcting the tilt angle of solar panel. As a result, a $24 \%$ increase in power was noticed with the inclusion of a solar tracker. The monitoring of a standalone solar panel was also carried out using the NodeMCU, Node-RED, Arduino, INA219 and multimeter setup. Except for some minor inaccuracy in the power output, the proposed system can easily work well in a solar power plant.

\section{REFERENCES}

NodeMGU. (2014). https://www.nodemcu.com/index_en.html

Node-RED. (n.d.). https://nodered.org/

Oukennou, A., Berrar, A., Belbhar, I., \& El Hamri, N. (2019). Low Cost IoT System for Solar Panel Power Monitoring. Colloque sur les Objets et systèmes Connectés, Ecole Supérieure de Technologie de Casablanca (Maroc), Institut Universitaire de Technologie d'Aix-Marseille (France), CASABLANCA, Morocco. ffhal-02298769f. https://hal.archives-ouvertes.fr/hal-02298769/ document

Symanovich, S. (n.d.). The future of Io T: 10 predictions about the Internet of Things. https://us.norton.com/ internetsecurity-iot-5-predictions-for-the-future-of-iot.html

Wholesale Solar. (2018). Tilt and Azimuth angle. https://www.wholesalesolar.com/blog/solar-panelazimuth-angle 